food, including bread, until the next report, which has been forwarded to me this day, January 29 , and which I transeribe.

"My DEAR Sir,-Enclosed you will receive my report, which I think will speak for itself. I can now reverse my tale, and say, ' the bones which were once seen are now hidden from sight;' I am, of course, with this increase of flesh much stronger. I feel some little difficulty in walking upstairs, but not to the extent I formerly did by any means; I get a free perspiration, my appetite is good, and the cramps are quitc gone. When I meet any one whom I have not seen for eight or nine days, they want to know if my face is not swelled; my clothes, which hung about me as though not belonging to me, I am obliged to alter in the buttons. I have found a good substitute for bread in parsnips. The fat ham had the desired effect on my bowels; of course, it checked my progress in weight, which has gradually risen thus :-

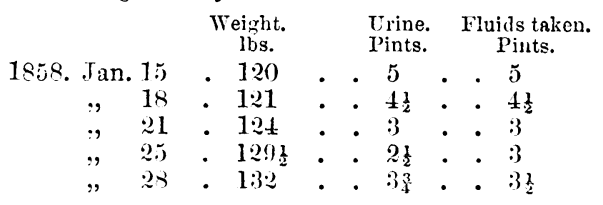

"I can now attend to business comfortably; I can walk four miles an hour well. Perspired freely last night in bed, and exertion to-day induces a moisture also."

The report gives a daily account of the quantity of fluid taken and the amount of urine voided; they are here set down by way of contrast with the increase of weight.

The analysis of the urine this day confirms the foregoing remarks on the positive improvement in health. Instead of presenting its usual amber-coloured clear character, it is now muddy, and deposits some lithates. The muddiness is removed by heat. It is acid, and of specific gravity 1032, and is found to contain only twenty grains per 1000 of sugar; indeed, the indications now are so faint, Mr. Heisch observes, that it is not easy to define the precise quantity, as before, by means of polarised light.

I refrain from any comment on the above facts, which are quite unprecedented in the treatment of this intractable disease. Upon a review of upwards of one hundred cases of diabetes, it has never fallen to my lot to witness such a marked, rapid, and satisfactory improvement, by any line of treatment, as that now under consideration.

59 , Berners Street, Middlesex Hospital, January 30th, 1858.

\section{ON THE MORTALITY OF INFANTS IN FOUND- LING INSTITUTIONS, AND GENERALLY, AS INFLUENCED BY THE ABSENCE OF BREAST-MILK.}

By C. H. F. Rocth, MI.D., Physician to the Samaritan Free Hospital for Women and Children; late Physician to the St. Pancras Royal Dispensary; etc.

\section{Pant II.}

ON THE advantages aNd Dangers OF Wet-Nersing. IN a former paper which I had the honour of reading before the Medical Society, I spoke of the causes of mortality in foundling hospitals, as opposed to those which obtain in a general population, and dwelt in particular on one-want of breast-milk. My remarks tended to show that the evil influence of this cause had been greatly exaggerated; the mortality being, in fact, rather due to other contingencies which I thei enumerated. I purpose now to consider the mortality of children as influenced by the diet selected, and to treat it especially under three heads.

I. As influenced by the kind of breast-milk supplied.

II. As influenced by the quality of any other animal's milk or compound given as a substitute.

IrI. As influenced by the vegretable food which is usually employed.

On the last occasion I had to allude to the little advantage usually derived from hospital experience to the profession. I have now to allude to one of the honourable exceptions, viz., the first and second Reports of the. Clinical Hospital for the Diseases of Children, in Stevenson Square, Manchester, pre pared by Drs. Merei and Whitehead, and kindly sent to me by the former gentleman. These are most able and philosophical documents, not a fact being asserted which is not substantiated by accurate statistical researches-documents like those which might be yearly produced by every hospital, and confer endless good to thousauds. I shall first, in a short summary, quote a few of those results which bear upon this portion of my subject.

1. In regard to age, seizures, and deaths, taling the two years together.

\begin{tabular}{|c|c|c|c|c|c|c|}
\hline \multirow{3}{*}{\multicolumn{2}{|c|}{$\begin{array}{l}\text { Under } 6 \text { months } \\
6 \text { months and under } 12\end{array}$}} & Seized. & & Died. & & er cent. \\
\hline & & 250 & .. & $4: 2$ & .. & 10.1 \\
\hline & & $2 \pi 1$ & .. & $2: 5$ & .. & 9.8 \\
\hline 1 to 2 years & . & \pm 50 & .. & $5 \%$ & .. & 12.6 \\
\hline 2 to 3 years & . & 285 & .. & 1:3 & .. & 4.5 \\
\hline 3 to 4 years & . & 055 & .. & $1 \pm$ & .. & 2.1 \\
\hline & . & $191 \%$ & & 151 & & 8.8 \\
\hline
\end{tabular}

From this it will bo seen that mortality is greatest under six months, and that under two years the preponderance of deaths is very great.

2. From the first report there were treated-

Developmental disorders, viz.:-

Feeble and retarded development, incluing com plication, with anrenia and slight degrees of rickets

Rachitis of decided forms $\quad . \quad 5 \quad . \quad . \quad . \quad . \quad 28$

Constitutional debility, including slight complieations, with anæmia, but no disorlers of development .

cases.

Diseases of the abdominal organs:-

Disordered digestion (loss of appetite, sickness, costiveness, diarrhœa)

Diarrhœa (mucous, serous, bilious) .

Dysentery. $.5 \cdot$.

Sporadic cholera . . . . . . . . . .

Enteritis . $\cdot{ }^{*}$

Rheumatism of stomach $\cdot \quad \cdot \quad \cdot \quad \cdot \quad \cdot \quad \cdot \quad$

Habitual constipation (severe) • • • . .

Mesenteric disease . . . 1

Chronic enlargement of liver . . . . . .

Hepatitis

Making a total of cases of disease of revelopment

Or per cent.

Deaths . . . . . . . . . 34

Taking, however, the $3 \pm$ deaths from various causes, 10 happened to children with bad development; diarrhøa was present, either as principal ailment or as a complication, in $20, i . \epsilon ., 60$ per cent. In 24 of the $3 \pm$ fatal cases, $i . c ., 70$ per cent., there was morbid localisation in the abdominal cavity.

From the second year's report, of 1545 patients, there were affected with -

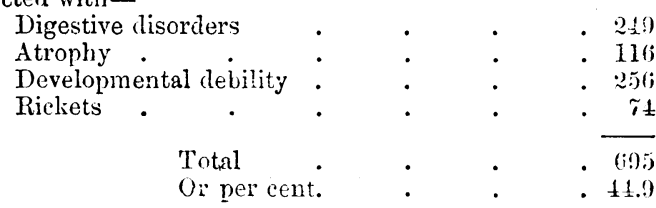

The greater number were dismissed cmed : !:3, however, died.

Of 117 deaths from sil causes, $9: 3$ deaths, or 79 per cent., were from diseases arising from defective or faulty nutrition, which was partly the direct and partly the co-operative cause of the fatal issue

of these 93,11 had a full supply of breast-milk up to nine months; but seven of the respective mothers had been delicate or sick, and only four healthy: 19 children had had a more or less sufficient supply of breast-milk, and bread food along with it, and from earliest infancy; 59 were brought up from birth or earliest infancy on bread food, in addition to scanty breast. milk; and 4 had no breast at all. Consequently, only a very small proportion of those who died (a little above 4 per cent.) had enjoyed a fully favourable alimentation.

The breast-milk of feeble or sickly women, and scantily secreted, judged according to its effects upon the respective nurselings and its chemical examination, is, in the great majority of cases, decidedly of unwholesome quality.

Altorether, about 60 per cent. of the children treated in this institution were brought up in an unfavourable manner.

From these statements will at once be perceived the extensive operation of two noxious agents-insufficient and unwholesome breast-milk, and early breail-feeding. 
The direct and baneful agency of want of good breast-milk may be inferred from the next table.

\section{Results observed in 1041 Children.} 0 or 62.0 milk alone to ninth month or Medium " 35 or 23.3 longer. Some to fifteenth, eigh- Badly " $\quad 21$ or 14 teenth, or twenty-fourth months.

Total ....... 150

2. Those who had breast-milk) Well developed 65 or 57.4 up to sixth, eighth, and ninth Medium ” 29 or 25.6 months; after which they were Badly " 18 or 15.9 partially weaned; about 20 per $\left.\begin{array}{l}\text { cent. of them partially receiving } \\ \text { for some months longer other food }\end{array}\right\}$ Total ....... 113 for some months longer other food
beside the breast.

3. Those having breast-milk) Well developed 110 or 51 moderately abundant and bread- Medium " 54 or 25 food along with it from birth or Badly " 52 or 24 early ages.

Total ....... 216

4. Children who from birth or Well developed 55 or 52 the age of two or three months, Medium " 29 or 28 . besides an abundance of breast- Badly " 21 or 20 milk (as stated by mothers), had received additional food, generally Total ....... 105 boiled bread and milk, or merely with water, sugar, and arrowroot.

5. Children who have had from Well developed 109 or 26.8 the earliest infancy a moderate Medium " 107 or 26.3 or small supply of breast-milk; Badly " $\quad 191$ or 45.9 some for a few months only, others up to nine, twelve, fifteen, or Total ....... 407 eighteen months, or longer, with other food from birth.

6. Children fed entirely by Well developed 5 or 10 hand, and , $^{\text {with no breast-milk at }}$ Medium " 13 or 20 all

$$
\begin{aligned}
& \text { Badly " } 32 \text { or } 6 \\
& \text { Total ....... } \overline{50}
\end{aligned}
$$

Among those noted as being of very good development-i.e., those most rapidly advanced in dentition, ossification of the skull, and facility of walking (most of these having commenced to walk before twelve, many at ten and eleven - -we find 59, of whom 43 had breast-milk alone to nine months and upwards, to twelve, fifteen, eighteen months, a few of them even longer; 8 had breast-milk alone to between six and nine months; eight only received, besides the breast, other kinds of food before the sixth month. It may be added, that the respective 59 mothers were at most not only healthy, but of strong constitutions, and had great abundance of milk.

Of the 1548 children treated in the second year, there were-

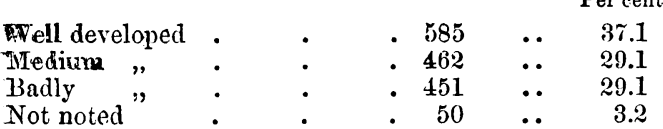

Of these, $2 \tau$ per cent. had a full supply of breast-milk, or at least for upwards of six months; 29 per cent. had a medium supply, with bread or other food; 38 per cent. had scanty breast-milk and some farinaceous food from birth or earliest infancy; 3 of them had no breast at all from birth or earliest infancy.

From these facts, we cannot otherwise than conclude that bringing up a child on its mother's breast-milk is, without doubt, the best method where the mother's milk is abundant. The worst is to bring up a child exclusively by hand; at least, in the way in which it is usually done.

These conclusions, however, it should be insisted on, valuwble as they are, apply' to towns only, and in which the artificial food supplied is not good. Of this last point, more anon. I think, however, sufficient evidence is now before us to justify the conclusion that, if a mother be healthy and have sufficient milk, it is her duty to suckle her child.

But supposing a mother cannot do so, should a wet nurse be selected or not? I think myself justified, in this view of the case, to lay it down as a rule never to decide at once upon the employment of a wet nurse, until the attempt has been made, at least for a few days, under medical supervision, and with proper care, to bring up the child by hand, and it has been found to fail. And this because-

(a) The employment of wet nurses frequently entails the death of the children deserted by them, at least in towns. 'Their development is at least almost always retarded, if not prevented altogether.

(b) It is attended with an increase of mortality in the children confided to these wet nurses.

(c) There is a risk of physically, as well as morally, injuring the children so confided.

(a) In Dr. Merei's and Whitehead's cases of the 40 children under treatment which had been brought up by hand, in the second year's report, 4 died, or 10 per cent. But, out of the 40 , only 4 , or 10 per cent., were well developed; 10 , or 25 per cent., medium developed; and 26 , or 65 per cent., badly developed. The figures above given on the two reports combined tell the same tale. It must always be so if children are in circumstances of poverty and want, combined with injudicious management. And here the mortality is even lower than might have been suspected; and probably this was due to the judicious treatment employed.

(b) The mere substitution of a hired wet nurse increases the mortality; for it should be borne in mind that the chances of life, precarious as they always are in a young infant, are rendered still more so by transferring a child to a wet nurse other than its mother. From a reference to the Annuaires of Mortality in Paris, Quetelet obtained nearly everywhere the same result, - that, in the first three months after birth, twice or three times as many children die as in the other months of the first year. Other authors, he says, have made the same observations; and from their inquiries they have thought to find the cause of this disproportion in the mortality in the habit which mothers have either of suckling their own children or of abandoning them to hired wet nurses. Here is what $\mathbf{M}$. Benoiston de Chateauneuf, in his excellent work on the Enfans Trouvés, says on this subject:- "It is true that, to preserve the life of a child, care does everything, and climate nothing, or very little; and Switzerland and Holland are the countries where the smallest number die. Is the explanation of this fact, already offered by Muret, to be found in the habit which all the mothers, at the foot of the Alps as on the borders of the Amstel, have of suckling their children them. selves? We cannot say; but we shall only add, that, having been curious to compare the mortality of children at nurse with that of children brought up in Paris, we obtained the following results. Of 100 children suckled by their mothers, 18 die in the first year; of the same number at nurse, 20 die." (Recherches sur la Population, Décès, etc., du Royaume des Pays Bas. Par A. Quetelet. F. 18, p. 142-3.)

The following facts, for which I am indebted to the kindness of Mr. Brownlow, the efficient Secretary to the Foundling Hospital, direct to a conclusion similar to that arrived at by Benoiston de Chateauneuf. From some parish registers given in the Report of the Special Committee to the Governors of the Foundling Hospital, it appears, also, the mortality is much greater among those children nursed by strange women, as compared to those nursed by their mothers. Thus, between the years 1762 and 1770 , the annual mortality was as follows from children of and under four years old.

Admitted :-

Foundlings

Illegitimate $\quad \cdot \quad \cdot \quad \cdot 5283$

Casual $\quad \cdot \quad \div \quad \div \quad \div 1821$

Legitimate $\quad \cdot \quad \cdot \quad . \quad+19562$

Total.$\overline{27543}$

Died :-

Nursed by their mothers . . . 1229

Nursed by workhouse nurses $\quad . \quad 5 \quad 2698$

Total . $\overline{392 \pi}$

Removed :-

To the Foundling Hospital ${ }^{*}$. 525

To their mothers . $\quad: \quad 3623$

To friends 2961

Total . . $\overline{7109}$ 
This gives a gross mortality of $14 \cdot 2$ per cent. upon admis. sions; or, out of 100 deaths, $31 \cdot 2$ will occur among those nursed by their own mothers, while 68.8 will occur among those nursed by the workhouse nurses. These numbers have, of course, no absolute value, as it is not stated how many children were nursed by their mothers, and how many by workhouse nurses. Still as, out of this number, only 877 were foundlings, and as many as 7109 were removed to the Foundling Hospital, mothers, or friends, we may presume this number only were not nursed by their own mothers at the workhouse. Deducting, also, those children who, as sent to the Foundling Hospital, were probably among the number previously included among foundlings admitted, we shall have about 7461 children who were probably nursed by the workhouse nurses, giving a mortality of $36 \cdot 1$ per cent. for such children to $6 \cdot 1$ per cent. for those nourished by their mothers. These numbers are doubtless exaggerated on both sides; but I think the reasoning adopted will justify our concluding that the risk of substituting a hired wet nurse for a mother is great, and that it will certainly increase the mortality.

The above reasons are sufficiently powerful to induce parents to put off the adoption of a hired wet nurse as long as possible. But, more than this, it is better, if it can be in any way accomplished, to put off the day for other reasons. First, there is often great difficulty to procure a fitting wet nurse. It sometimes happens that a suitable one for a given child eannot be found. I have known as many as seven wet nurses successively to be tried before one was obtained to suit; and this no doubt because, as Burdach states, the milk only of that child's mother would have agreed with it ; and, vice vers $\hat{a}$, that child's mother's milk would not have proved useful to another child. Secondly, the later the employment of a wet nurse is put off (unless, indeed, it is so manifestly necessary and indicated that the child's death appears exceedingly probable), the better chance there is of the child living through it, since the chances of life increase with the age of the child. This I. showed in my former paper; but the following table from Burdach is confirmatory of it.

Mortality in different quarters of the first year (Burdach, Physiologie, vol. iv, s. 523, p. 387.)

$$
\text { Brussels. Broeck. Berlin. Hamburg. Paris. }
$$$$
1 \text { in } 1 \text { in } 1 \text { in } 1 \text { in } 1 \text { in }
$$

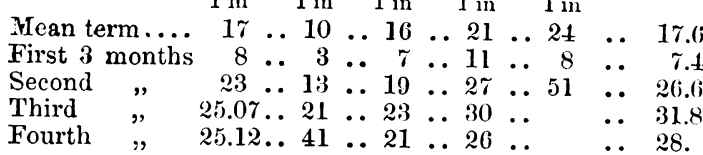

(c) But there may be a state of health present in the mother which renders this change essential. If she is weak or pale, hysterical to a degree; if there be copious leucorrhœa, but particularly if there be headache and a sensation of sinking at the epigastrium; if the sight become impaired,-the mother should desist. This defect in the sight will become blindness if the nursing be prolonged-a blindness often persistent, and the least curable. Moreover, as shown by Jis. Merei and Whitehead, such milk is not only injurious to the child at the time, but is insufficient for its proper development. As such, it is noxious. Then, again, the child's mother may be dead. Or, lastly, the child whom an attempt has been made to bring up by hand is in a state of dangerous atrophy, diarrhœa, etc. In such a case, there must be a change; and $\mathrm{a}$ wet nurse must be selected. In this choice, we must have regard, lest we injure the child to be nursed, to-

1. Her moral qualifications.

2. Her physical qualifications.

Moral Qualifications. The lesser mortality among child ren suckled by their own mothers is no doubt due to the greater care and assiduity with which women will tend their own children. But there is another: it is want of experience in the wet nurse. And the question here suggests itself, Is it not due in great measure to the selection made? It is usual in our profession to recommend as a nurse an unmarried woman who has fallen; and the reason assigned is, that her milk is less likely to suffer, because she has no husband or children to fret after; or, if she has fallen more than once, she is less likely to fret after a child left behind, her habits having inured her to this separation. Now, is this a moral act on the part of those who make such selections? Is vice to be recom. mended by the preference so given, and the child of the unfortunate mother almost certainly sacrificed? It is a cruel alternative; and, although circumstances of necessity may arise to justify the adoption of such a course, still I think we are bound to set our faces against a system so pregnant with mischief to society.

But, apart from the moral act, I must say that the use of a nurse who has fallen for the first time is very dangerous. She is quite inexperienced; and the child entrusted to her care is, therefore, very likely to suffer. If such a woman is selected, she should be used rather as the animal which feeds the child, and the supervision of the infant entirely taken away from her. When one who has fallen more than once is selected, it is true, the objection of inexperience does not apply; but the moral objection is greater. Her conduct betokens a depraved and passionate nature; and, like a species of insanity, it may be conveyed to the infant, to his permanent injury in life. I am sure I have noticed this. Upon this point Burdach states "The organism of a child is not passive to the impressions that act upon him. He developes in the direction of the first influence submitted to him, and hence does not suck out in consequence a character opposed to that of the milk on which he feeds. The thing is manifest in itself, and, moreover, well exemplified by the thousands of infants which are fed on cow or goat's milk. If the popular opinion leads us to believe in a moral assimilation of character; if it be pernitted, in speaking figuratively, to say of a cruel man, that he was suckled by a tigress,-all that is true at the bottom is, that the mode of animal life of those beings who are suckled determines the quality of the milk; and that this in like manner in fluences on the mode of animal life of the suckling child.' (Burdach, iv, 384.) And surely, if we look at the subject philosophically; if the child, while in the womb, has an independent life, yet derives much of his nourishment from the mother during the nine months he exists in that womb,-is the suckling infant less influenced by the woman he suckles during the nine months or year in which he continues to derive his nourishment, and that almost exclusively, from her milk? But further still; if those psychologists are right who, in the present day, ascribe much of the criminal tendencies of some minds to hereditary taint, whereby, as if it were spiritually as materially, the sins of the fathers are visited on the children; if there be anything in blood, as conveying good or bad inclinations,-shall we say that a vicious wet nurse will not be a material link in contaminating the child who feeds on milk ex tracted from her blood? Doubtless it must be so.

It may not be inopportune here to repeat a story which re. fers to the queen of one of the then reigning monarchs of Sweden, who, contrary to royal etiquette, would give nourishment to her own infant, preferiing to follow Nature's rule and dictum to that of courts or modes. Her example, it would seem, was followed by the ladies of the court; for, at the time the story refers to, one of the ladies in waiting upon her majesty was a suckling mother too. The queen one day was absent longer than usual from the royal babe, who began to cry from hunger. The lady before referred to, taking compassion upon the infant, took it to her bosom, and gave it nourishment from her own breast. The queen, coming in soon after, and learning what had been taking place, with great indignation seized the child, and, putting her finger in its mouth, forced it to be sick, and to reject the milk it had just talen, ex. claiming the while that "her infant should have none but royal blood flow in its veins ". 'This is a good lesson, if not to queens, to mothers of lesser degree.

Let us beware how far we advise the selection of a fallen woman as a wet nurse. I would not, however, in regard to the former class, wish my words to be misconstrued. Woman is to me always an object of interest; and, even in her most degraded state, she is an object for Christian pity and reformation. Many are rather sinned against than sinning-the victim of some villain, who has deceived a too confiding love. If we are assured of this, if the woman be one of a class not previously depraved, and such as may be admitted in the Female Penitentiary, New Road, I think I should give her the preference to a married woman. If she is carefully watched in tending on the child, and her own child is carefully looked to, we are giving that woman an opportunity of gaining an honest livelihood, and once more reclaiming a lost position in society; but if she be a harlot in taste and habit, a virtuous household is not her proper domicile.

[To be continued.] 